\title{
Voltaire et le livre, textes réunis par François Bessire et Françoise Tilkin
}

Stefania Carli

\section{(2) OpenEdition}

1 Journals

\section{Edizione digitale}

URL: http://journals.openedition.org/studifrancesi/5963

DOI: 10.4000/studifrancesi.5963

ISSN: 2421-5856

\section{Editore}

Rosenberg \& Sellier

\section{Edizione cartacea}

Data di pubblicazione: 1 mai 2011

Paginazione: 174-175

ISSN: 0039-2944

\section{Notizia bibliografica digitale}

Stefania Carli, «Voltaire et le livre, textes réunis par François Bessire et Françoise Tilkin», Studi Francesi [Online], 163 (LV | I) | 2011, online dal 30 novembre 2015, consultato il 13 janvier 2021. URL: http:// journals.openedition.org/studifrancesi/5963 ; DOI: https://doi.org/10.4000/studifrancesi.5963

Questo documento è stato generato automaticamente il 13 janvier 2021.

\section{(c) $(1) \odot \odot$}

Studi Francesi è distribuita con Licenza Creative Commons Attribuzione - Non commerciale - Non opere derivate 4.0 Internazionale. 


\title{
Voltaire et le livre, textes réunis par François Bessire et Françoise Tilkin
}

\author{
Stefania Carli
}

\section{NOTIZIA}

Voltaire et le livre, textes réunis par François BESSIRE et Françoise TILKIN, Ferney-Voltaire, Centre International d'Etude du XVIII ${ }^{\mathrm{e}}$ siècle, 2009 («Publications de la Société Voltaire», vol. 1), pp. VIII + 323 .

1 Il presente volume, il primo della collana «Publications de la Société Voltaire», raccoglie gli interventi presentati ad un convegno tenuto dalla suddetta Société alla Bibliothèque Nationale su Voltaire et le livre, ai quali sono stati aggiunti alcuni altri contributi riguardanti sempre il patriarca di Ferney. Esso si suddivide in tre parti, tutte incentrate sull'analisi del rapporto che colui che è considerato l'«Homme du livre» per eccellenza ha avuto con i librai che lo hanno editato o che comunque hanno avuto a che fare con le sue opere. La prima sezione «Voltaire et le monde du livre» è dedicata alle relazioni che lo scrittrore intrattenne con gli altri protagonisti del mondo editoriale dell'epoca. Il primo articolo (Kees VAN STRIEN, Voltaire et ses libraires d'Amsterdam, Ledet et Desbordes, 1731-1742, pp.3-24) analizza per esempio le opere di Voltaire pubblicate dai fratelli Ledet con la collaborazione di Jacques Desbordes in Olanda: non meno di quindici testi e di due edizioni delle CEuvres. Edwin VAN MEERKERK (L'échange épistolaire de Voltaire et $\mathrm{Du}$ Sauzet, libraire d'Amsterdam, 1738-1740, pp.25-36) riscopre invece quarantasei lettere tra l'illustre autore francese e il libraio olandese Du Sauzet, mentre David SMITH si dedica allo studio di cinque edizioni delle opere complete pubblicate tra il 1748 e il 1752 (Les relations entre Voltaire et ses libraires: Walther, Machuel et Lambert, 1748-1752, pp. 37-46). L'edizione del 1748 di Walther è poi approfondita da Martin FONTIUS e David SMITH in collaborazione con Andrew BROWN (La publication en 1748 des "Euvres complètes de Mr de Voltaire" par Georg Konrad Walther, de Dresde, pp.47-66). Quest'ultimo analizza inoltre le relazioni dell'autore con Grasset, il principale editore di 
Voltaire tra il 1764 e il 1778 (Andrew BROWN, Gabriel Grasset éditeur de Voltaire, pp.67-106), mentre Dominique VARRY si sofferma sull'ultima edizione delle opere complete pubblicata quando lo scrittore era ancora in vita (L'édition encadrée des œeuvres de Voltaire: une collaboration entre imprimeurs-libraires genevois et lyonnais?, pp. 107-116). Concludono la prima parte del volume i contributi di Wallace KIRSOP (Voltaire et les souscriptions, pp. 117-124), di Françoise BLÉcHET (Voltaire et la police du livre, pp. 125-138) e di Jean-Daniel CANDAUX (Voltaire, auteur permis, approuvé, privilégié, pp. 139-146).

2 La seconda sezione, «Circulation et réception du livre voltairien», segue le vicissitudini dei testi pubblicati da Voltaire. Condannati o celebrati, messi segretamente in circolazione o contraffatti, essi divennero all'epoca un fondamentale strumento di comunicazione. Questa seconda parte si apre con i contributi di Charlotte SIMONIN (L"idole" et ses "balafres" ou Voltaire et ses livres à travers la correspondance de Mme de Graffigny, pp. 149-172) e di Patricia MÉNISSIER (De l'acquisition à la circulation du livre: le rôle des amies de Voltaire, pp.173-184), entrambi incentrati sui rapporti intrattenuti tra Voltaire e le donne delle Lumières. Daniel DRoIXHE studia due pièces che all'epoca furono oggetto di contraffazione: Le Caffé (1760) e Olympie (1762) (Genève, Paris ou Rouen? Quel modèle pour les contrefaçons liégeoises du "Caffé" et d'“Olympie" de Voltraire?, pp. 185-196). Roger BERGERET prende a sua volta in esame l'influenza esercitata dall'avvocato Christin sugli ultimi anni di vita di Voltaire, influenza che traspare dalla loro corrispondenza (Christin et Voltaire: un exemple d'écriture militante et de diffusion du livre au siècle des Lumières, pp. 197-216), mentre Didier MASSEAU (Voltaire et la pratique du livre: le regard des antiphilosophes, pp. 217-229) analizza le polemiche e le denunce degli avversari di Voltaire sulla concezione che quest'ultimo aveva del libro.

3 La terza parte, «De la lecture à l'écriture», è consacrata all'elaborazione del testo da parte dell'autore. Bruno BERNARD si sofferma sulla figura di Voltaire his-torien (Citations et références dans les ouvrages historiques de Voltaire, pp. 233-242), mentre Christophe PAILLARD studia il personaggio di Wagnière, secrétaire dello scrittore ( Un dictionnaire vivant»: Jean-Louis Wagnière témoin des pratiques de lecture et d'écriture de Voltaire, pp. 243-256). Chiudono il volume tre interventi sulla narrativa di Voltaire, quelli di Ugo DIONNE (Voltaire chapitré. Observations sur le dispositif voltairien, pp. 257-270), di Muriel CATTOOR (Opérations à livre ouvert, pp. 271-278) e di Éric FRANCALANZA (Le livre dans les contes de Voltaire, pp. 279-289). 